\title{
Animal models used in the research of nanoparticles for cardiovascular diseases
}

\author{
Caijuan Dong • Aiqun Ma $\cdot$ Lijun Shang $(\mathbb{D}$
}

Received: 5 November 2020 / Accepted: 16 July 2021 / Published online: 10 August 2021

(C) The Author(s), under exclusive licence to Springer Nature B.V. 2021

\begin{abstract}
Cardiovascular disease (CVD) is the leading cause of mortality and morbidity worldwide. Tremendous progress has been made in the prevention and treatment of CVD; however, there are still lots of limitations and new technology is needed. Nanoparticles have been studied recently for CVD due to their nanoscale size and unique properties, and hold a potential to be a novel therapy for the treatment. To test the safety and effectiveness of drugloaded nanoparticles for CVD prior to human studies, animal disease models are unavoidably needed. This review summarized the animal models used in the research of nanoparticles for CVD and provided a generic picture of current use of CVD animal models according to the different types of diseases which should be prioritized when considering the application of nanoparticles in treating CVD. This review would be useful resources not only for life science researchers and clinicians but also for those from chemistry and materials sciences background who may not have a systematic knowledge about CVD animal models.
\end{abstract}

C. Dong $\cdot$ A. Ma $\cdot$ L. Shang

Department of Cardiovascular Medicine, First Affiliated Hospital of Xi' an Jiaotong University, Xi'an 710054 Shaanxi, China

L. Shang

Faculty of Life Science, Northwest University, Xi'an 710032

Shaanxi, China

L. Shang $(\bowtie)$

School of Human Sciences, London Metropolitan University, London N7 8DB, UK

e-mail: 1.shang@londonmet.ac.uk
Keywords Animal model - Cardiovascular disease . Nanoparticles · Drug delivery

\section{Introduction}

Cardiovascular disease (CVD), including coronary artery disease, peripheral vascular disease, congestive heart failure, and atrial fibrillation, is the leading cause of mortality and morbidity worldwide (Joseph et al. 2017). Substantial improvements have been achieved in life expectancy and living quality due to better prevention and enhanced treatment for CVD, but there is still an urgent need for the drug innovation. Nanoparticles, defined as heterogeneous group of substances that vary in size $(10-100 \mathrm{~nm})$, have emerged as a potential candidate for drug delivery system. Nanoparticles possess several unique properties such as enhanced biocompatibility, reduced toxicity, and prolonged retention time (Dong et al. 2018). Besides, certain nanoparticles can serve as a drug due to their anti-inflammatory and antioxidant effects (Zhang et al. 2018). In this review, we summarized in vivo preclinical studies of nanoparticles for CVD using various animal models. These established animal models provided useful information to guide further experiments particularly when designing and choosing nanoparticles and would be useful resources not only for life science researchers and clinicians but also for those from chemistry and materials sciences background who may not have a 
systematic knowledge about CVD animal models (Zaragoza et al. 2011).

\section{Opportunities and challenges of nanoparticles for CVD treatment}

The epidemiological transition in the twentieth century was marked by a significant decrease in deaths and disability from communicable diseases and an increase in non-communicable diseases (NCDs). Among NCDs, CVD is the leading cause of mortality and morbidity worldwide and accounts for approximately one-third of all deaths globally. According to a newly published data, prevalent cases of total CVD nearly doubled from 271 million in 1990 to 523 million in 2019, and the number of CVD deaths steadily increased from 12.1 million in 1990 to 18.6 million in 2019 (Roth et al. 2020). Both genetic and environmental factors are implicated in the development of CVD, which makes the treatment even more complicated.

Developing relevant CVD drugs is the common strategy for treatment. Aspirin, statins, $\beta$-blockers, angiotensin-converting enzyme inhibitors/angiotensin receptor blockers, and other drugs have been validated in many large clinical trials to improve clinical outcomes in individuals with stable CVD (Leong et al. 2017). Further development on novel therapeutics such as using a delivery system to improve drug half-life and reduce side effects becomes a hot research topic. As the molecular processes underlying CVD become better defined, there are growing studies to intervene CVD using gene therapy. However, nuclear acid is easy to be identified and diminished and requires a carrier to protect them interacting with internal environment. Finding a delivery machine also seems a logical tool to bring gene therapy to fruition (Herrera et al. 2018).

Nanoparticles including inorganic nanoparticles, liposomes, and extracellular vesicles seem to be a good choice for this purpose. The nanoscale of nanoparticles enables themselves to cross natural barriers and enter into target cells more easily. Hence, drugs wrapped in nanoparticles could protect themselves from interactions with the surrounding environment and degradation, and further enhance the concentration in the targeted tissues. Additionally, nanoparticles can achieve controlled drug release by constructing a release system in response of internal stimuli such as $\mathrm{pH}$, redox state, and the presence of biomolecules as well as external stimuli such as light and magnetic field (Dong et al. 2018). For example, lipid nanoparticles are the carriers most used in clinical trials for therapeutics, due to their pronounced advantages over other delivery systems such as easy preparation, high biocompatibility, and biodegradability. Unfortunately, being synthetic and quite "unnatural," lipid nanoparticles can be toxic and induce immune response at high doses, particularly in the condition where the required dose is high or frequent application is required. However, these effects could be overcome by selecting proper lipid components (Zhang 2005; Xue et al. 2014). Up to now, several nano-formulations of lipid nanoparticles have been approved for human use. For example, BNT162b2, a kind of vaccine against COVID-19 and adopted lipid nanoparticles as vehicles, has been put into clinical use (No Author 2020). All these predict a promising application of using nanoparticles for the treatment of CVD.

\section{Animal models for studying nanoparticles as a treatment for CVD}

Animal models remain the best tool to investigate the novel pharmacological treatment of nanoparticles for CVD. The complicated nature of CVD presents challenges to test the application of nanoparticles in treating CVD. Better understanding of all animal models used is therefore the key in the study. In this paper, the most commonly used CVD animal models and their usages in testing nanoparticle applications for the treatment of CVD are reviewed. We focused on the animal models according to the type of CVDs and explained the complexity of choosing proper animal models to best mimic the pathological conditions of CVDs. We did not exam and compare which nanoparticle should be chosen and their potentially complicated properties when interacting with animals due to very random data in the limited applications. However, the properties of nanoparticles, especially when interacting with physiological system is the important aspects to be investigated in each individual study. Interdisciplinary collaboration with experts in chemistry and materials would greatly improve our understanding of how to best use nanoparticles to treat CVDs in this aspect.

The common animal models are mainly created based on cardiovascular pathological conditions, such as hypertension, atherosclerosis, myocardial infarction, and myocardial ischemia-reperfusion (Table 1), and the 
availability and feasibility of choice of animals for these cardiovascular pathological conditions.

Both small animals such as mice and rats and large animals such as rabbits, canines, swine, sheep, and nonhuman primates are used in the study and they have their own advantages and disadvantages. For example, small animals are easier to handle and house, have a shorter gestation time, and have lower maintenance cost than larger animal models (Zaragoza et al. 2011). These features make small animals the most used model for cardiac physiology and pathology, genetics, pharmacology, and long-term survival studies. In addition, the availability of transgenic and knockout strains and little difficulty in creating new genetic modifications make the mouse one of the most attractive models for research. Nevertheless, large animals have similar cardiovascular system to human at both the organ and cellular levels, thus transitions from the researches in those large animals to human researches are more likely to repeat and the results obtained are also ready to use. In the following sections, we summarize all those animal models according to the type of CVD and how they have been used to test the applications of nanoparticles in treating CVD.
Hypertension animal models

Hypertension is known for persistently elevated blood pressure in the arteries. High blood pressure is a major risk factor for many diseases such as coronary artery diseases and stroke which usually does not cause obvious symptoms. Hypertension is classified into essential hypertension and secondary hypertension. Human essential hypertension is a complicated disease that involved both genetic and environmental factors. It has been demonstrated that genetic predisposition, excessive salt intake, over-stress, and hyperactivation of renin-angiotensin-aldosterone system are involved in the development of hypertension. Therefore, hypertension animal models are established mainly based on the above etiology.

There are four major hypertension models produced so far. Spontaneously Hypertensive Rat (SHR) is the internationally recognized animal model which is closest to human essential hypertension and has been widely used in basic research on essential hypertension and antihypertensive drug screening (Doris 2017). Fructose-(Klein and Kiat 2015), dexamethasone-(Beg et al. 2015), and DOCA-(Chadha et al. 2012) induced

Table 1 Common animal models for CVDs

\begin{tabular}{|c|c|c|}
\hline $\begin{array}{l}\text { Cardiovascular } \\
\text { disease or } \\
\text { pathological } \\
\text { conditions }\end{array}$ & Intervention & Typical features \\
\hline Hypertension & Spontaneous; fructose; dexamethasone; DOCA & Elevated blood pressure \\
\hline Atherosclerosis & $\begin{array}{l}\text { High cholesterol; continuous intimal injury through } \\
\text { catheter, balloon angioplasty, or nitrogen exposure }\end{array}$ & $\begin{array}{l}\text { Lipid abnormality with elevated triglyceride } \\
\text { and other liver enzymes; atherosclerotic } \\
\text { plaques on the wall of arteries featured } \\
\text { by foam cells }\end{array}$ \\
\hline $\begin{array}{l}\text { Myocardial } \\
\text { infarction }\end{array}$ & Permanent LAD ligation; ISO & $\begin{array}{l}\text { Elevated myocardial enzymes and inflammatory } \\
\text { cytokines; reduced ejection fraction; macroscopic } \\
\text { appearance of scar; obvious histological alterations } \\
\text { such as fibrosis and left ventricular remodeling. }\end{array}$ \\
\hline $\begin{array}{l}\text { Myocardial } \\
\text { ischemia-- } \\
\text { reperfusion }\end{array}$ & Partial LAD ligation and blood reperfusion & Similar to MI model \\
\hline $\begin{array}{l}\text { Pulmonary arterial } \\
\text { hypertension }\end{array}$ & Monocrotaline; hypoxia & $\begin{array}{l}\text { Thick wall of the pulmonary peripheral arteries; right } \\
\text { ventricular remodeling }\end{array}$ \\
\hline Arrhythmia & Calcium chloride; barium chloride & Disorders of heart rhythm \\
\hline $\begin{array}{l}\text { Abdominal aortic } \\
\text { aneurysm }\end{array}$ & $\begin{array}{l}\text { Chronic infusion of angiotensin II into low-density li- } \\
\text { poprotein receptor-deficient }\left(\mathrm{LDLr}^{-/-}\right) \text {mice in com- } \\
\text { bination with a high-fat diet; elastase infusion } \\
\text { of the aorta }\end{array}$ & $\begin{array}{l}\text { Macroscopic appearance of the abdominal aorta; } \\
\text { macrophage activation within the aortic media }\end{array}$ \\
\hline
\end{tabular}

Abbreviations: DOCA, deoxycorticosterone acetate salt; $L A D$, anterior descending coronary artery; ISO, isoproterenol 
hypertension models are all secondary hypertension models, which can mimic hypertension combined with insulin resistance, hypertension caused by activation of the mineralocorticoid receptor and elevated aldosterone, respectively. The hypertension animal model is characterized with elevated blood pressure.

As mentioned above, human essential hypertension is a complex disease associated with both genetic and environmental factors. Therefore, one single animal model may not be able to fully mimic the hypertensive responses and is therefore not sufficient to explain the antihypertensive effects of drugs when using nanoparticle as its delivery system. Therefore, various hypertension animal models are needed and results from these different models need to be compared before any conclusion can be drawn.

The current hypertension animal models used in the study of nanoparticles for the treatment of hypertension are summarized in Table 2. The nanoparticles combined with antihypertensive drugs such as nifedipine and lercanidipine hydrochloride enhanced the drug efficacy by prolonging the retention time in vivo. But those effects have not been tested for a long period of time and this is the same to their toxicity and side effect. Generally, antihypertensive drugs need to be continuously used and even for the rest of life. The animal models used at the moment normally last for couple of months as its maximum. Therefore, conclusion obtained should be further tested and verified. Nevertheless, these applications suggested that it was feasible to using drugloaded nanoparticles for the treatment of hypertension.

\section{Atherosclerosis animal models}

Atherosclerosis, characterized by sub-endothelial accumulation of fatty substances called plaques, is the main underlying cause of myocardial infarction and stroke (Sluimer and Daemen 2009). It usually takes decades to form plaques with various inflammatory cytokines and immune cells contributing to the process. Rats and mice were inherently resistant to atherosclerosis. Therefore, transgenic models such as $\mathrm{LDLR}^{-/-}$mouse (Ishibashi et al. 1993) and apoE ${ }^{-/-}$mouse were established to develop atherosclerosis through gene knockout technology. However, gene knockout animals are rather expensive and may impose a substantial financial pressure to any research as well as limit the number of samples obtained. The rabbit is used as the ideal alternate animal for experimental atherosclerosis by high-cholesterol diet or repeated or continuous intimal injury through catheter, balloon angioplasty, or nitrogen exposure (Zaragoza et al. 2011). The rabbit atherosclerosis model is a no plaque rupture model while porcine atherosclerosis models are valid to investigate the plaque rupture and restenosis. The highcholesterol diet-induced atherosclerosis models present lipid abnormality with elevated triglyceride and other liver enzymes, and atherosclerotic plaques on the wall of arteries featured by foam cells. The external injuryinduced atherosclerosis models exhibit atherosclerotic plaques without abnormal lipid profiles.

Table 3 summarizes the studies using nanoparticles for the treatment of atherosclerosis. Some modified nanoparticles like oligonucleotide functionalized nanoparticles could be specifically recognized by foam cells, which may serve as a potential delivery vehicle and therefore is worth for future study (Sharma et al. 2010). Superparamagnetic iron oxide nanoparticles for example could reach the target region under external magnetic gradient. This opens up the opportunity for further investigations aiming both to improve targeting efficacy and to develop the potential "magnetic drug targeting"-based approaches to therapy of arterial injuries and/or atherosclerotic plaques (Matuszak et al. 2018). In most of the study, drug-loaded with nanoparticles showed reduced lesion size and inflammatory responses than free drug in atherosclerosis animal model, suggesting that nanoparticles may be a promising strategy to prevent atherosclerosis. However, there are also some studies which did not show any antiatherogenic effects with administration of nanoformulated drugs while enhanced accumulation of drugs in the desired regions were observed (Matuszak et al. 2018). Therefore, selecting optimal drugs turns to be crucial and important.

Myocardial Infarction animal models

Myocardial infarction (MI) occurs when blood flow decreases or stops at certain part of the heart, causing damage to cardiomyocytes. MI is a life-threatening disease and can cause sudden death. Victims survived from MI often suffer from adverse ventricular remodeling, which is also known as heart failure. Therefore, it is essential to explore new therapy strategies to rescue the ischemic cardiomyocytes and attenuate ventricular remodeling. It has been revealed that myocardial hypertrophy, fibrosis, inflammation, mitochondrial 


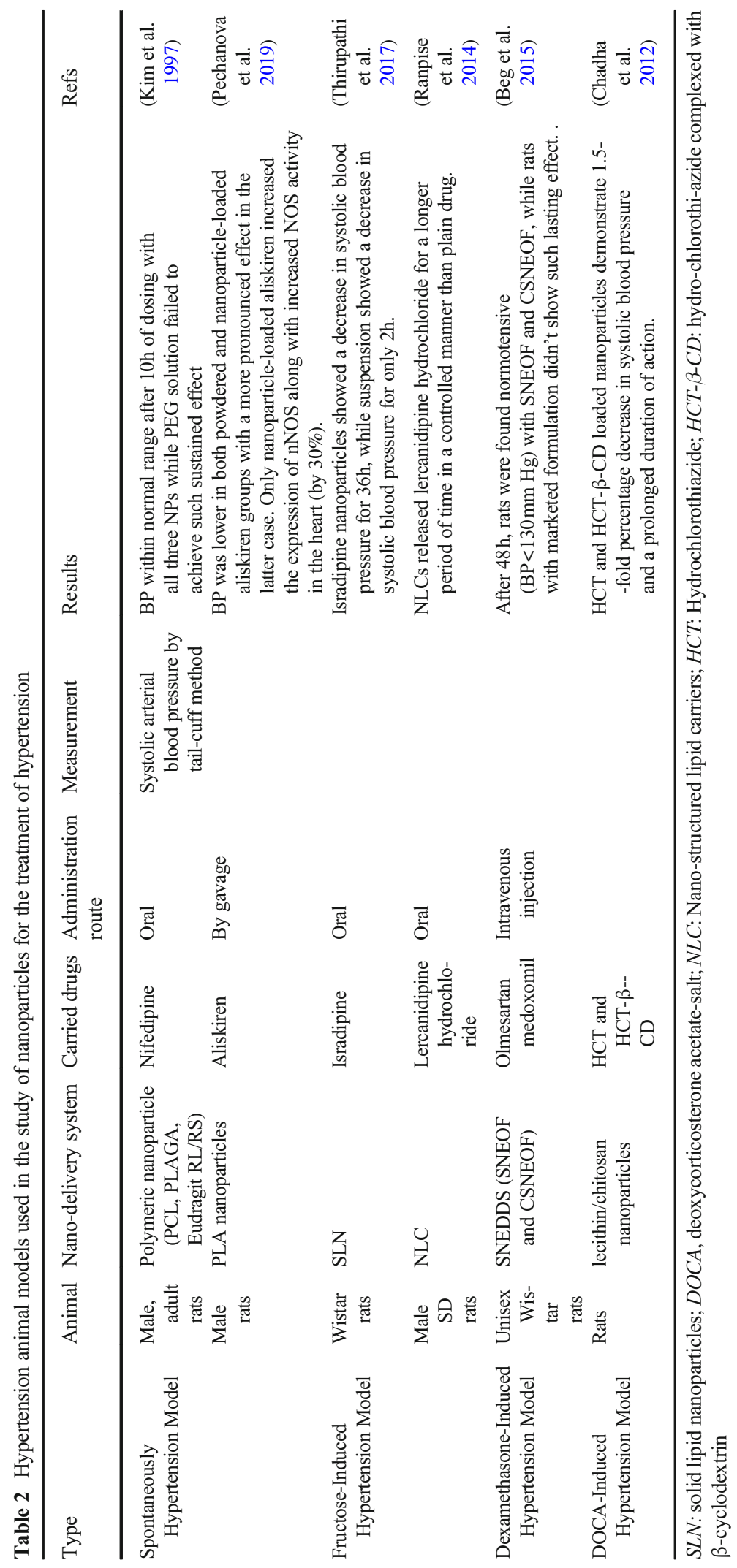


dysfunction, and autophagy/apoptosis are all involved in the progression of post-infarct ventricular remodeling. Using drug delivery system of nanoparticles carrying with cardioprotective agents to target any of the mechanisms above will benefit the dying cardiomyocytes. To examine their effectiveness, appropriate animal models need to be chosen to imitate human myocardial infarction as much as possible. Surgical ligation MI model and isoproterenol-induced MI model are current well-received models.

The surgical ligation MI model is made by ligating the left anterior descending coronary artery (LAD). Rat is dominantly used in the respect of heart damage because, while rats share many of the advantages with mice, their larger size greatly facilitates surgical operations. The mortality in surgical ligation MI models is higher than other non-traumatic MI models because the animals receiving thoracotomy often die from complications such as pneumothorax. However, after training and practice, the ligation method has higher stability than other methods. The myocardial infarction is more thorough, and the size of the infarct size is positively correlated with the height of the ligation site.

Isoproterenol (ISO)-induced MI model mimics sympathetic activation in the pathogenesis of myocardial infarction. ISO-induced MI model is widely adopted in promoting chronic myocardial infarction due to the lower mortality rate and less complexed procedure compared to the surgical ligation MI model. However, the infarct area caused by this method occasionally shows non-necrotic myocardium. Besides, the infarct area mainly distributes on the left ventricular wall and septum, especially near the apex. This method is also used for establishing the heart failure model and hyperthyroid heart disease model (Zhang et al. 2018).

The preferred large animal model of heart damage is the pig, because the collateral coronary circulation and arterial anatomy of pigs and humans are very similar and infarct size can be accurately predicted. These MI animal models present elevated myocardial enzymes, reduced ejection fraction, and obvious histological alterations such as fibrosis and left ventricular remodeling.

Table 4 briefly summarizes the MI animal models used in the study of nanoparticles for the treatment of acute myocardial infarction or post-infarct heart failure. Improved cardiac function and decreased infarct size were noticed in the MI animal model treated with empty nanoparticles or drug-loaded nanoparticles. Nucleic acid nanotherapies were investigated in MI animal model as well. Nox2-siRNA nanoparticles were observed to prevent upregulation of Nox 2 and significantly recover cardiac function in mice receiving LAD ligation. In the past few years, several cardiac gene therapy clinical trials were conducted with aim at inducing therapeutic angiogenesis in the ischemic heart. However, the efficiency of cardiac gene delivery remains a major hurdle preventing success (Cannata et al. 2020). Nanoparticles could address a breakthrough in delivery efficiency and hold a great promise for cardiac gene therapy.

Myocardial ischemia-reperfusion animal models

Myocardial ischemia-reperfusion (I/R) injury occurs when blood supply returns to the heart after a period of ischemia (Lejay et al. 2016). The possible mechanisms of myocardial I/R injury are as follows: (1) the outbreak of oxygen free radicals; (2) $\mathrm{Ca}^{2+}$ ovedoad; (3) mitochondrial dysfunction; (4) inflammation; (5) energy metabolism disorders. Myocardial I/R injury is a vital negative factor influencing the therapeutic efficacy for the MI victims who accept revascularization such as percutaneous transluminal coronary intervention (PCI) and coronary artery bypass grafting (CABG). The I/R animal model used is normally based on surgical ligation MI model. The difference is that left anterior descending coronary artery is partially ligated to achieve reperfusion in I/R model, while in MI model, it is completed ligated. The myocardial $\mathrm{I} / \mathrm{R}$ animal model established by this method can better simulate human myocardial ischemia-reperfusion. Besides, isolated Langendorf $\mathrm{I} / \mathrm{R}$ heart is often used for the ex vivo study of myocardial $\mathrm{I} / \mathrm{R}$ injury. Since the isolated heart is detached from nerve innervation and systemic humoral factors, the heart rate, pre-and post-load, perfusion pressure, and other factors can be controlled. It is therefore especially suitable to study the effects of some single factors on cardiac function and metabolism without interference effects of related factors. However, the conclusions from isolated I/R heart are worthy of consideration when extending to humans because this model is isolated from inner environment. Small animals such as mice and rats are admired by researchers to build myocardial I/R animal model and the reasons are similar to MI animal model. At present, there is no agreeable conclusion on the exposure time of ischemia and reperfusion because they are affected by the size of the animal and the tolerance of the organ or tissue to ischemia and hypoxia. 


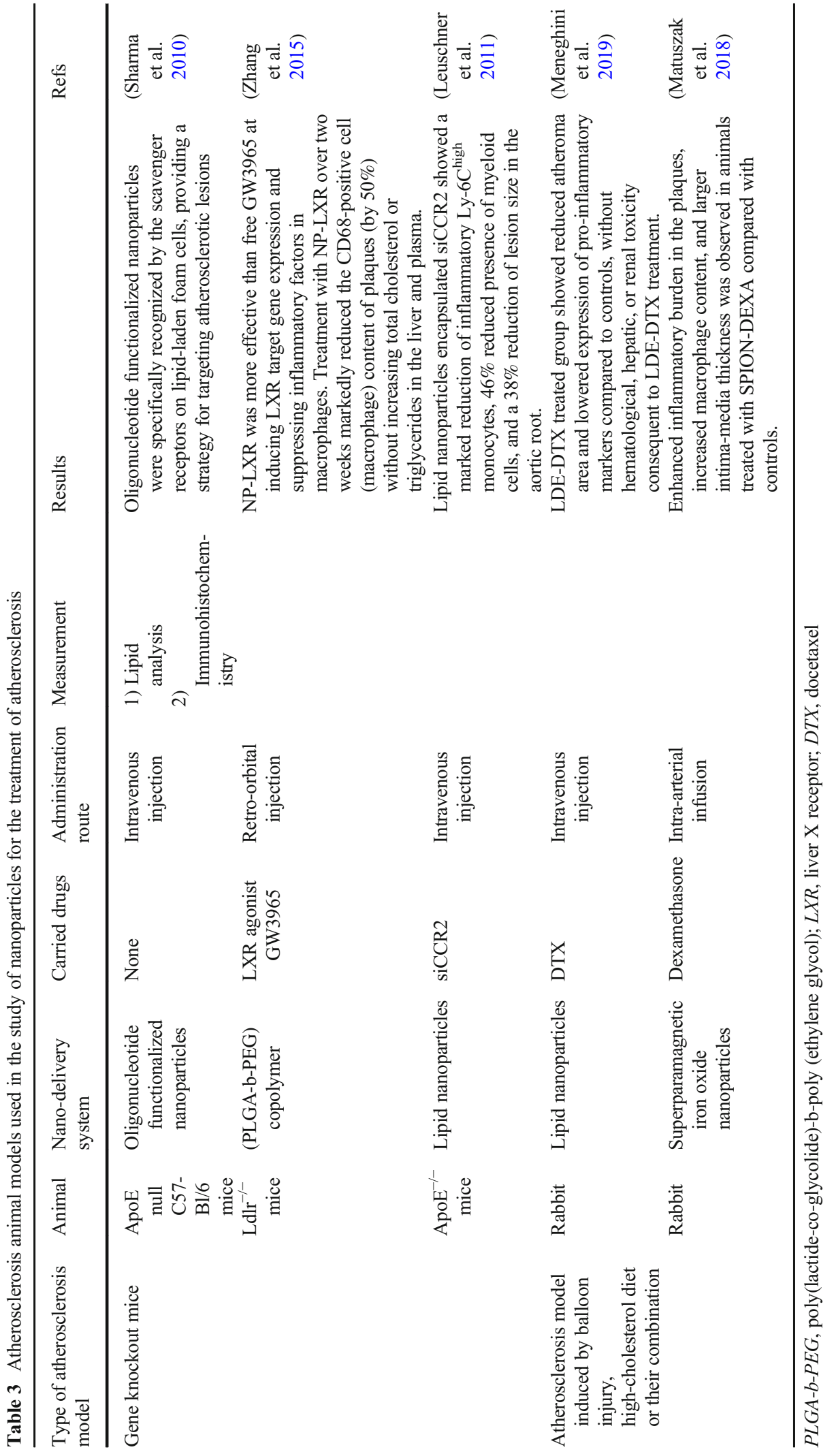




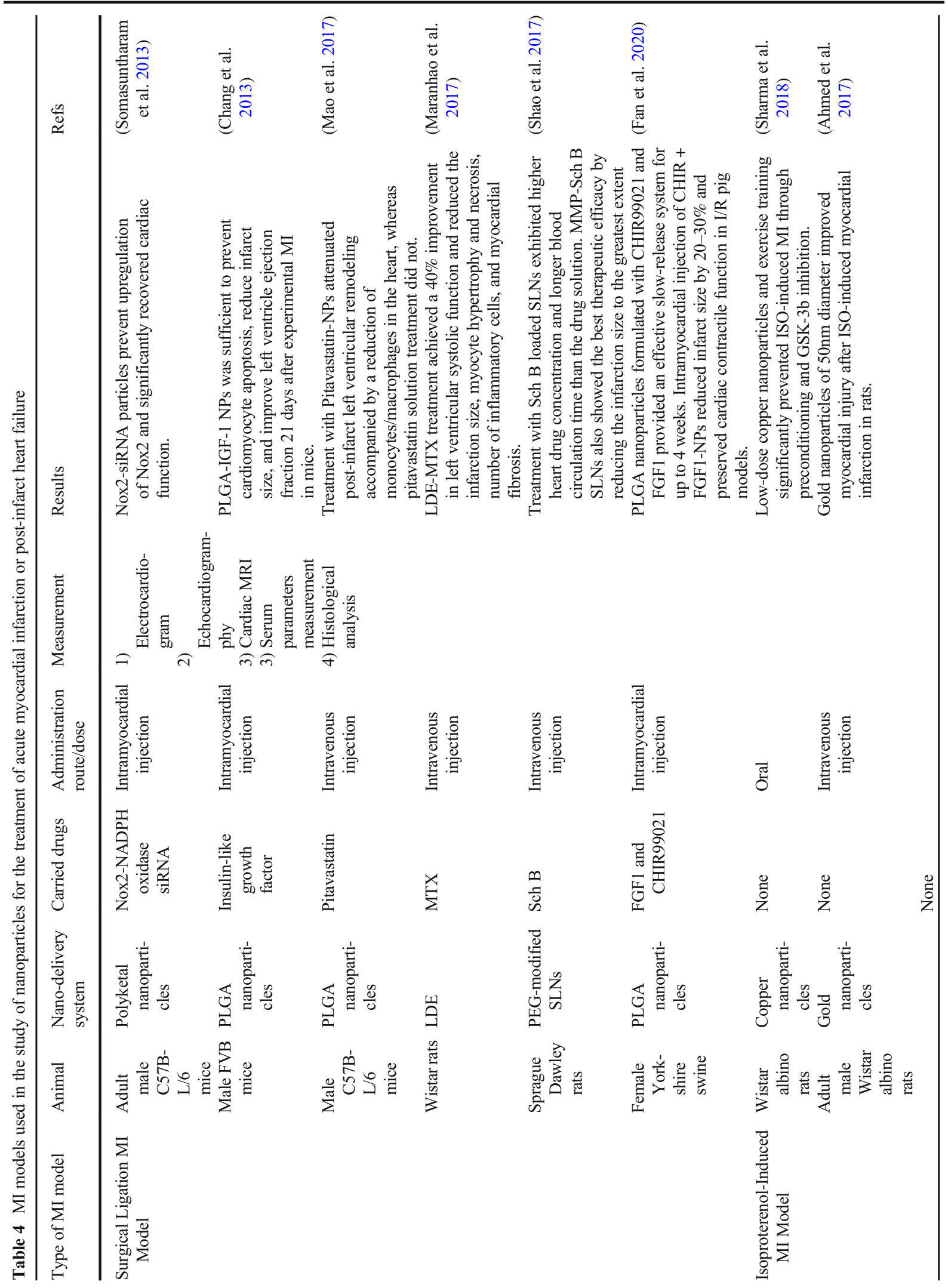




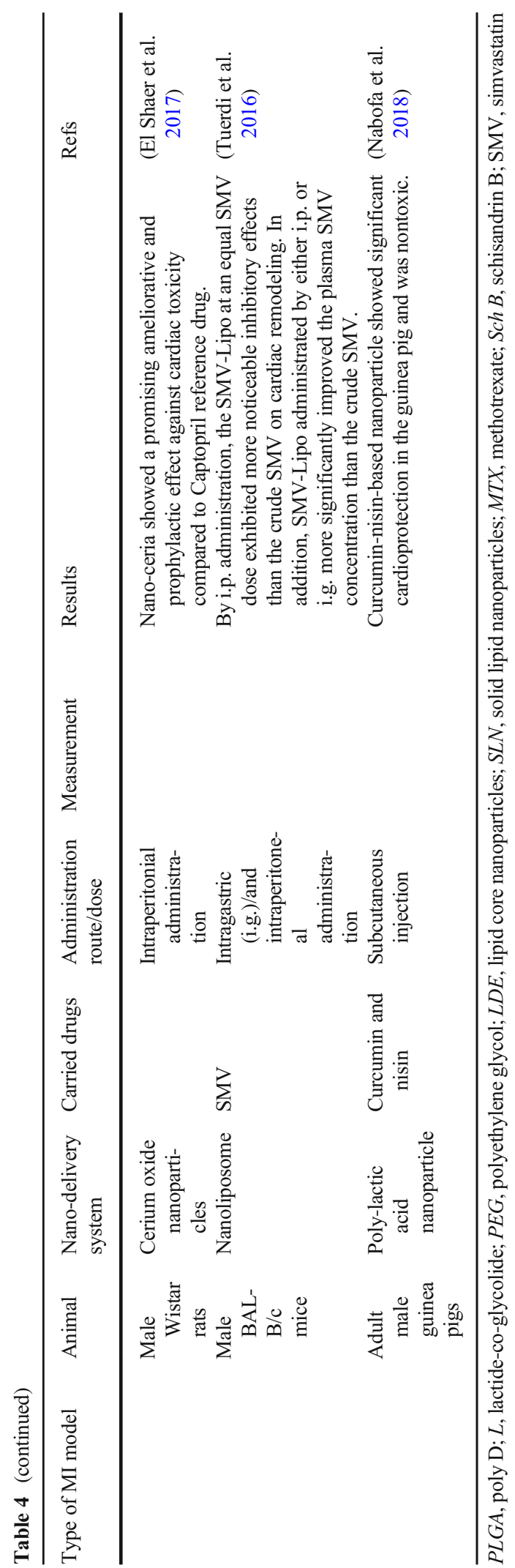

Table 5 briefly reviewed the I/R animal models used in the study of nanoparticles for the treatment of myocardial I/R injury. PLGA nanoparticles and other inorganic nanoparticles were tested either as empty or loaded with most used clinical drugs on these animal models. For majority of the study, reduced inflammatory responses, apoptosis, and lesion size were observed in myocardial I/R animal models treated with nanoformulated drugs, indicating the potential of nano-drug delivery system for the treatment of $I / R$ injury. For example, silver nanoparticles increased the level of cytokines and aggravated I/R injury. For the concern of safety, silver nanoparticles are not proper nanoparticles for the treatment of $I / R$ injury.

Other animal models

There are some other animal models adopted to study the effect of nanoparticles for CVD, such as pulmonary arterial hypertension model, arrhythmia model, and abdominal aortic aneurysm model. These animal models are more specific targeted for individual CVD conditions. Overall, drug-loaded nanoparticles showed cardioprotective effects in these animal models. Prostaglandin I2 and its analogues (such as beraprost sodium, BPS) are beneficial for the treatment of PAH. Intravenous administration of BPS nanoparticles (once per week, $20 \mu \mathrm{g} / \mathrm{kg}$ ) protected against monocrotalineinduced and hypoxia-induced pulmonary arterial remodeling and right ventricular hypertrophy. The extent of this protection was similar to that observed with oral administration (once per day, $100 \mu \mathrm{g} / \mathrm{kg}$ ) of BPS alone (Ishihara et al. 2015). The beneficial effects of BPS-NP on PAH animal models seem to be mediated by its sustained release and tissue targeting profiles. BPS nanoparticles may be useful for the treatment of PAH patients due to reduced dosages and frequency of BPS administration.

\section{Conclusion}

CVD animal models remain the best tool to understand the mechanism of human CVD and validate the novel pharmacological therapeutics. No single animal model can perfectly duplicate the human disease and there are other concerns to be considered when choosing animal models such as cost, infrastructure, and the requirement for specialized personnel. Choosing a model that best 


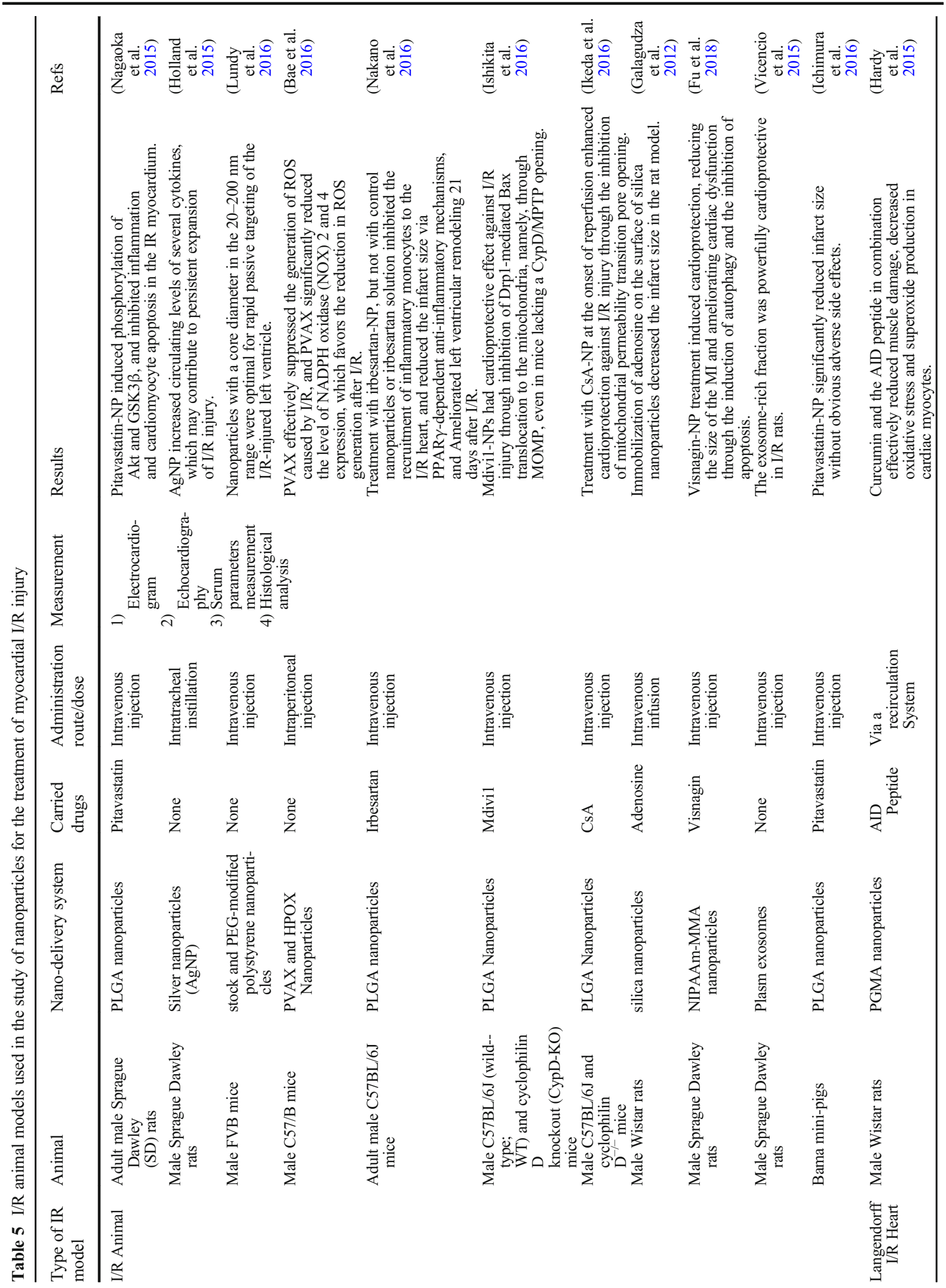


reflect on the aspect of disease being investigated can certainly help to explore how nanoparticles can be best used for CVD. The effects of nanoparticles in various preclinical animal models of CVD approved that nanoparticles as a delivery vehicle can significantly improve the therapeutic efficacy of the drug and reduce doses and frequency of drug administration through sustained release and tissue-specific targeting. Nanoparticles are also ideal delivery carrier for the gene therapy. Therefore, nanoparticles possess a strong potential for clinical translation in CVD. However, establishing more reliable large animal models and choosing more effective therapeutic genes or drugs should be prioritized when testing the nanoparticle application.

Funding This work was financially supported by the Natural Science Foundation of Shaanxi Province, P. R. China (No. 2019JM-543). Professor Lijun Shang was an honorary visiting Professor to Northwest University and the First Affiliated Hospital of Xi'an Jiaotong University.

\section{Declarations}

Conflict of interest The authors declare no conflict of interest.

\section{References}

Ahmed SM, Abdelrahman SA, Salama AE (2017) Efficacy of gold nanoparticles against isoproterenol induced acute myocardial infarction in adult male albino rats. Ultrastruct Pathol. 41(2):168-185

Bae S, Park M, Kang C, Dilmen S, Kang TH, Kang DG, Ke Q, Lee SU, Lee D, Kang PM (2016) Hydrogen peroxideresponsive nanoparticle reduces myocardial ischemia/ reperfusion injury. J Am Heart Assoc 5(11):e003697

Beg S, Sharma G, Thanki K, Jain S, Katare OP, Singh B (2015) Positively charged self-nanoemulsifying oily formulations of olmesartan medoxomil: systematic development, in vitro, ex vivo and in vivo evaluation. Int J Pharm. 493(1-2):466482

Cannata A, Ali H, Sinagra G, Giacca M (2020) Gene therapy for the heart lessons learned and future perspectives. Circ Res. 126(10):1394-1414

Chadha R, Bhandari S, Kataria D, Gupta S, Singh JD (2012) Exploring the potential of lecithin/chitosan nanoparticles in enhancement of antihypertensive efficacy of hydrochlorothiazide. J Microencapsul. 29(8):805-812

Chang MY, Yang YJ, Chang CH, Tang ACL, Liao WY, Cheng FY, Yeh CS, Lai JJ, Stayton PS, Hsieh PCH (2013) Functionalized nanoparticles provide early cardioprotection after acute myocardial infarction. J Control Release. 170(2): 287-294 
Dong C, Ma A, Shang L (2018) Nanoparticles for postinfarct ventricular remodeling. Nanomedicine (Lond). 13(23): 3037-3050

Doris PA (2017) Genetics of hypertension: an assessment of progress in the spontaneously hypertensive rat. Physiol Genomics. 49(11):601-617

El Shaer SS, Salaheldin TA, Saied NM, Abdelazim SM (2017) In vivo ameliorative effect of cerium oxide nanoparticles in isoproterenol-induced cardiac toxicity. Exp Toxicol Pathol. 69(7):435-441

Fan C, Oduk Y, Zhao M, Lou X, Tang Y, Pretorius D, Valarmathi MT, Walcott GP, Yang J, Menasche P, Krishnamurthy P, Zhu W, Zhang J (2020) Myocardial protection by nanomaterials formulated with CHIR99021 and FGF1. JCI Insight 5(12):e132796

Fu H, Li X, Tan J (2018) NIPAAm-MMA nanoparticle-encapsulated visnagin ameliorates myocardial ischemia/reperfusion injury through the promotion of autophagy and the inhibition of apoptosis. Oncol Lett. 15(4):4827-4836

Galagudza M, Korolev D, Postnov V, Naumisheva E, Grigorova Y, Uskov I, Shlyakhto E (2012) Passive targeting of ischemic-reperfused myocardium with adenosine-loaded silica nanoparticles. Int J Nanomedicine. 7:1671-1678

Hardy N, Viola HM, Johnstone VP et al (2015) Nanoparticlemediated dual delivery of an antioxidant and a peptide against the L-Type $\mathrm{Ca} 2+$ channel enables simultaneous reduction of cardiac ischemia-reperfusion injury. ACS Nano. 9(1):279-289

Herrera VL, Colby AH, Ruiz-Opazo N, Coleman DG, Grinstaff MW (2018) Nucleic acid nanomedicines in Phase II/III clinical trials: translation of nucleic acid therapies for reprogramming cells. Nanomedicine (Lond). 13(16):20832098

Holland NA, Becak DP, Shannahan JH, Brown JM, Carratt SA, Winkle L, Pinkerton KE, Wang CM, Munusamy P, Baer DR, Sumner SJ, Fennell TR, Lust RM, Wingard CJ (2015) Cardiac ischemia reperfusion injury following instillation of $20 \mathrm{~nm}$ citrate-capped nanosilver. J Nanomed Nanotechnol 6: 006

Ichimura K, Matoba T, Nakano K, Tokutome M, Honda K, Koga JI, Egashira K (2016) A translational study of a new therapeutic approach for acute myocardial infarction: nanoparticle-mediated delivery of pitavastatin into reperfused myocardium reduces ischemia-reperfusion injury in a preclinical porcine model. PLoS One. 11(9):e0162425

Ikeda G, Matoba T, Nakano Y, Nagaoka K, Ishikita A, Nakano K, Funamoto D, Sunagawa K, Egashira K (2016) Nanoparticlemediated targeting of cyclosporine A enhances cardioprotection against ischemia-reperfusion injury through inhibition of mitochondrial permeability transition pore opening. Sci Rep. 6:20467

Ishibashi S, Brown MS, Goldstein JL, Gerard RD, Hammer RE, Herz J (1993) Hypercholesterolemia in low density lipoprotein receptor knockout mice and its reversal by adenovirusmediated gene delivery. J Clin Invest. 92(2):883-893

Ishihara T, Hayashi E, Yamamoto S, Kobayashi C, Tamura Y, Sawazaki R, Tamura F, Tahara K, Kasahara T, Ishihara T, Takenaga M, Fukuda K, Mizushima T (2015) Encapsulation of beraprost sodium in nanoparticles: analysis of sustained release properties, targeting abilities and pharmacological activities in animal models of pulmonary arterial hypertension. J Control Release. 197:97-104

Ishikita A, Matoba T, Ikeda G, Koga J, Mao Y, Nakano K, Takeuchi O, Sadoshima J, Egashira K (2016) Nanoparticlemediated delivery of mitochondrial division inhibitor 1 to the myocardium protects the heart from ischemia-reperfusion injury through inhibition of mitochondria outer membrane permeabilization: a new therapeutic modality for acute myocardial infarction. J Am Heart Assoc 5(7):e003872

Joseph P, Leong D, McKee M, Anand SS, Schwalm JD, Teo K, Mente A, Yusuf S (2017) Reducing the global burden of cardiovascular disease, Part 1: the epidemiology and risk factors. Circ Res. 121(6):677-694

Kim YI, Fluckiger L, Hoffman M, Lartaud-Idjouadiene I, Atkinson J, Maincent P (1997) The antihypertensive effect of orally administered nifedipine-loaded nanoparticles in spontaneously hypertensive rats. Br J Pharmacol. 120(3): 399-404

Klein AV, Kiat H (2015) The mechanisms underlying fructoseinduced hypertension: a review. J Hypertens. 33(5):912-920

Lejay A, Fang F, John R, van JAD, Barr M, Thaveau F, Chakfe N, Geny B, Scholey JW (2016) Ischemia reperfusion injury, ischemic conditioning and diabetes mellitus. $\mathrm{J}$ Mol Cell Cardiol. 91:11-22

Leong DP, Joseph PG, McKee M, Anand SS, Teo KK, Schwalm JD, Yusuf S (2017) Reducing the global burden of cardiovascular disease, Part 2: prevention and treatment of cardiovascular disease. Circ Res. 121(6):695-710

Leuschner F, Dutta P, Gorbatov R, Novobrantseva TI, Donahoe JS, Courties G, Lee KM, Kim JI, Markmann JF, Marinelli B, Panizzi P, Lee WW, Iwamoto Y, Milstein S, Epstein-Barash H, Cantley W, Wong J, Cortez-Retamozo V, Newton A, Love K, Libby P, Pittet MJ, Swirski FK, Koteliansky V, Langer R, Weissleder R, Anderson DG, Nahrendorf M (2011) Therapeutic siRNA silencing in inflammatory monocytes in mice. Nat Biotechnol. 29(11):1005-1010

Lundy DJ, Chen KH, Toh EK, Hsieh PC (2016) Distribution of systemically administered nanoparticles reveals a sizedependent effect immediately following cardiac ischaemiareperfusion injury. Sci Rep. 6:25613

Mao Y, Koga JI, Tokutome M, Matoba T, Ikeda G, Nakano K, Egashira K (2017) Nanoparticle-mediated delivery of pitavastatin to monocytes/macrophages inhibits left ventricular remodeling after acute myocardial infarction by inhibiting monocyte-mediated inflammation. Int Heart J. 58(4):615-623

Maranhao RC, Guido MC, de Lima AD et al (2017) Methotrexate carried in lipid core nanoparticles reduces myocardial infarction size and improves cardiac function in rats. Int $\mathrm{J}$ Nanomedicine. 12:3767-3784

Matuszak J, Lutz B, Sekita A, Zaloga J, Alexiou C, Lyer S, Cicha I (2018) Drug delivery to atherosclerotic plaques using superparamagnetic iron oxide nanoparticles. Int J Nanomedicine. 13:8443-8460

Meneghini BC, Tavares ER, Guido MC, Tavoni TM, Stefani HA, Kalil-Filho R, Maranhão RC (2019) Lipid core nanoparticles as vehicle for docetaxel reduces atherosclerotic lesion, inflammation, cell death and proliferation in an atherosclerosis rabbit model. Vascul Pharmacol. 115:46-54

Nabofa WEE, Alashe OO, Oyeyemi OT, Attah AF, Oyagbemi AA, Omobowale TO, Adedapo AA, Alada ARA (2018) 
Cardioprotective effects of curcumin-nisin based poly lactic acid nanoparticle on myocardial infarction in guinea pigs. Sci Rep. 8(1): 16649

Nagaoka K, Matoba T, Mao Y, Nakano Y, Ikeda G, Egusa S, Tokutome M, Nagahama R, Nakano K, Sunagawa K, Egashira K (2015) A new therapeutic modality for acute myocardial infarction: nanoparticle-mediated delivery of pitavastatin induces cardioprotection from ischemiareperfusion injury via activation of $\mathrm{PI} 3 \mathrm{~K} / \mathrm{Akt}$ pathway and anti-inflammation in a rat model. PLoS One. 10(7):e0132451

Nakano Y, Matoba T, Tokutome M, Funamoto D, Katsuki S, Ikeda G, Nagaoka K, Ishikita A, Nakano K, Koga JI, Sunagawa K, Egashira K (2016) Nanoparticle-mediated delivery of irbesartan induces cardioprotection from myocardial ischemia-reperfusion injury by antagonizing monocytemediated inflammation. Sci Rep. 6:29601

No Author (2020) Nanomedicine and the COVID-19 vaccines. Nat Nanotechnol 15(12):963

Pechanova O, Barta A, Koneracka M, Zavisova V, Kubovcikova M, Klimentova J, Trk J, Zemancikova A, Cebova M (2019) Protective effects of nanoparticle-loaded aliskiren on cardiovascular system in spontaneously hypertensive rats. Molecules 24(15):2710

Ranpise NS, Korabu SS, Ghodake VN (2014) Second generation lipid nanoparticles (NLC) as an oral drug carrier for delivery of lercanidipine hydrochloride. Colloids Surf B Biointerfaces. 116:81-87

Roth GA, Mensah GA, Johnson CO, Addolorato G, Ammirati E, Baddour LM, Barengo NC, Beaton AZ, Benjamin EJ, Benziger CP, Bonny A, Brauer M, Brodmann M, Cahill TJ, Carapetis J, Catapano AL, Chugh SS, Cooper LT, Coresh J, Criqui M, DeCleene N, Eagle KA, Emmons-Bell S, Feigin VL, Fernández-Solà J, Fowkes G, Gakidou E, Grundy SM, He FJ, Howard G, Hu F, Inker L, Karthikeyan G, Kassebaum N, Koroshetz W, Lavie C, Lloyd-Jones D, Lu HS, Mirijello A, Temesgen AM, Mokdad A, Moran AE, Muntner P, Narula J, Neal B, Ntsekhe M, Moraes de Oliveira G, Otto C, Owolabi M, Pratt M, Rajagopalan S, Reitsma M, Ribeiro ALP, Rigotti N, Rodgers A, Sable C, Shakil S, Sliwa-Hahnle K, Stark B, Sundström J, Timpel P, Tleyjeh IM, Valgimigli M, Vos T, Whelton PK, Yacoub M, Zuhlke L, Murray C, Fuster V, Roth GA, Mensah GA, Johnson CO, Addolorato G, Ammirati E, Baddour LM, Barengo NC, Beaton A, Benjamin EJ, Benziger CP, Bonny A, Brauer M, Brodmann M, Cahill TJ, Carapetis JR, Catapano AL, Chugh S, Cooper LT, Coresh J, Criqui MH, DeCleene NK, Eagle KA, Emmons-Bell S, Feigin VL, Fernández-Sola J, Fowkes FGR, Gakidou E, Grundy SM, He FJ, Howard G, Hu F, Inker L, Karthikeyan G, Kassebaum NJ, Koroshetz WJ, Lavie C, Lloyd-Jones D, Lu HS, Mirijello A, Misganaw AT, Mokdad AH, Moran AE, Muntner P, Narula J, Neal B, Ntsekhe M, Oliveira GMM, Otto CM, Owolabi MO, Pratt M, Rajagopalan S, Reitsma MB, Ribeiro ALP, Rigotti NA, Rodgers A, Sable CA, Shakil SS, Sliwa K, Stark BA, Sundström J, Timpel P, Tleyjeh II, Valgimigli M, Vos T, Whelton PK, Yacoub M, Zuhlke LJ, Abbasi-Kangevari M, Abdi A, Abedi A, Aboyans V, Abrha WA, Abu-Gharbieh E, Abushouk AI, Acharya D, Adair T, Adebayo OM, Ademi Z, Advani SM, Afshari K, Afshin A, Agarwal G, Agasthi P, Ahmad S, Ahmadi S, Ahmed MB, Aji B, Akalu Y, AkandeSholabi W, Aklilu A, Akunna CJ, Alahdab F, al-Eyadhy A,
Alhabib KF, Alif SM, Alipour V, Aljunid SM, Alla F, Almasi-Hashiani A, Almustanyir S, al-Raddadi RM, Amegah AK, Amini S, Aminorroaya A, Amu H, Amugsi DA, Ancuceanu R, Anderlini D, Andrei T, Andrei CL, Ansari-Moghaddam A, Anteneh ZA, Antonazzo IC, Antony B, Anwer R, Appiah LT, Arabloo J, Ärnlöv J, Artanti KD, Ataro Z, Ausloos M, Avila-Burgos L, Awan AT, Awoke MA, Ayele HT, Ayza MA, Azari S, B DB, Baheiraei N, Baig AA, Bakhtiari A, Banach M, Banik PC, Baptista EA, Barboza MA, Barua L, Basu S, Bedi N, Béjot Y, Bennett DA, Bensenor IM, Berman AE, Bezabih YM, Bhagavathula AS, Bhaskar S, Bhattacharyya K, Bijani A, Bikbov B, Birhanu MM, Boloor A, Brant LC, Brenner H, Briko NI, Butt ZA, Caetano dos Santos FL, Cahill LE, Cahuana-Hurtado L, Cámera LA, Campos-Nonato IR, Cantu-Brito C, Car J, Carrero JJ, Carvalho F, CastañedaOrjuela CA, Catalá-López F, Cerin E, Charan J, Chattu VK, Chen S, Chin KL, Choi JYJ, Chu DT, Chung SC, Cirillo M, Coffey S, Conti S, Costa VM, Cundiff DK, Dadras O, Dagnew B, Dai X, Damasceno AAM, Dandona L, Dandona R, Davletov K, de la Cruz-Góngora V, de la Hoz FP, de Neve JW, Denova-Gutiérrez E, Derbew Molla M, Derseh BT, Desai R, Deuschl G, Dharmaratne SD, Dhimal M, Dhungana RR, Dianatinasab M, Diaz D, Djalalinia S, Dokova K, Douiri A, Duncan BB, Duraes AR, Eagan AW, Ebtehaj S, Eftekhari A, Eftekharzadeh S, Ekholuenetale M, el Nahas N, Elgendy IY, Elhadi M, el-Jaafary SI, Esteghamati S, Etisso AE, Eyawo O, Fadhil I, Faraon EJA, Faris PS, Farwati M, Farzadfar F, Fernandes E, Fernandez Prendes C, Ferrara P, Filip I, Fischer F, Flood D, Fukumoto T, Gad MM, Gaidhane S, Ganji M, Garg J, Gebre AK, Gebregiorgis BG, Gebregzabiher KZ, Gebremeskel GG, Getacher L, Obsa AG, Ghajar A, Ghashghaee A, Ghith N, Giampaoli S, Gilani SA, Gill PS, Gillum RF, Glushkova EV, Gnedovskaya EV, Golechha M, Gonfa KB, Goudarzian AH, Goulart AC, Guadamuz JS, Guha A, Guo Y, Gupta R, Hachinski V, Hafezi-Nejad N, Haile TG, Hamadeh RR, Hamidi S, Hankey GJ, Hargono A, Hartono RK, Hashemian M, Hashi A, Hassan S, Hassen HY, Havmoeller RJ, Hay SI, Hayat K, Heidari G, Herteliu C, Holla R, Hosseini M, Hosseinzadeh M, Hostiuc M, Hostiuc S, Househ M, Huang J, Humayun A, Iavicoli I, Ibeneme CU, Ibitoye SE, Ilesanmi OS, Ilic IM, Ilic MD, Iqbal U, Irvani SSN, Islam SMS, Islam RM, Iso H, Iwagami M, Jain V, Javaheri T, Jayapal SK, Jayaram S, Jayawardena R, Jeemon P, Jha RP, Jonas JB, Jonnagaddala J, Joukar F, Jozwiak JJ, Jürisson M, Kabir A, Kahlon T, Kalani R, Kalhor R, Kamath A, Kamel I, Kandel H, Kandel A, Karch A, Kasa AS, Katoto PDMC, Kayode GA, Khader YS, Khammarnia M, Khan MS, Khan MN, Khan M, Khan EA, Khatab K, Kibria GMA, Kim YJ, Kim GR, Kimokoti RW, Kisa S, Kisa A, Kivimäki M, Kolte D, Koolivand A, Korshunov VA, Koulmane Laxminarayana SL, Koyanagi A, Krishan K, Krishnamoorthy V, Kuate Defo B, Kucuk Bicer B, Kulkarni V, Kumar GA, Kumar N, Kurmi OP, Kusuma D, Kwan GF, la Vecchia C, Lacey B, Lallukka T, Lan Q, Lasrado S, Lassi ZS, Lauriola P, Lawrence WR, Laxmaiah A, LeGrand KE, Li MC, Li B, Li S, Lim SS, Lim LL, Lin H, Lin Z, Lin RT, Liu X, Lopez AD, Lorkowski S, Lotufo PA, Lugo A, M NK, Madotto F, Mahmoudi M, Majeed A, Malekzadeh R, Malik AA, Mamun AA, Manafi N, Mansournia MA, Mantovani LG, Martini S, Mathur MR, 
Mazzaglia G, Mehata S, Mehndiratta MM, Meier T, Menezes RG, Meretoja A, Mestrovic T, Miazgowski B, Miazgowski T, Michalek IM, Miller TR, Mirrakhimov EM, Mirzaei H, Moazen B, Moghadaszadeh M, Mohammad Y, Mohammad DK, Mohammed S, Mohammed MA, Mokhayeri Y, Molokhia M, Montasir AA, Moradi G, Moradzadeh R, Moraga P, Morawska L, Moreno Velásquez I, Morze J, Mubarik S, Muruet W, Musa KI, Nagarajan AJ, Nalini M, Nangia V, Naqvi AA, Narasimha Swamy S, Nascimento BR, Nayak VC, Nazari J, Nazarzadeh M, Negoi RI, Neupane Kandel S, Nguyen HLT, Nixon MR, Norrving B, Noubiap JJ, Nouthe BE, Nowak C, Odukoya OO, Ogbo FA, Olagunju AT, Orru H, Ortiz A, Ostroff SM, Padubidri JR, Palladino R, Pana A, Panda-Jonas S, Parekh U, Park EC, Parvizi M, Pashazadeh Kan F, Patel UK, Pathak M, Paudel R, Pepito VCF, Perianayagam A, Perico N, Pham HQ, Pilgrim T, Piradov MA, Pishgar F, Podder V, Polibin RV, Pourshams A, Pribadi DRA, Rabiee N, Rabiee M, Radfar A, Rafiei A, Rahim F, Rahimi-Movaghar V, Ur Rahman MH, Rahman MA, Rahmani AM, Rakovac I, Ram P, Ramalingam S, Rana J, Ranasinghe P, Rao SJ, Rathi P, Rawal L, Rawasia WF, Rawassizadeh R, Remuzzi G, Renzaho AMN, Rezapour A, Riahi SM, Roberts-Thomson RL, Roever L, Rohloff P, Romoli M, Roshandel G, Rwegerera GM, Saadatagah S, Saber-Ayad MM, Sabour S, Sacco S, Sadeghi M, Saeedi Moghaddam S, Safari S, Sahebkar A, Salehi S, Salimzadeh H, Samaei M, Samy AM, Santos IS, Santric-Milicevic MM, Sarrafzadegan N, Sarveazad A, Sathish T, Sawhney M, Saylan M, Schmidt MI, Schutte AE, Senthilkumaran S, Sepanlou SG, Sha F, Shahabi S, Shahid I, Shaikh MA, Shamali M, Shamsizadeh M, Shawon MSR, Sheikh A, Shigematsu M, Shin MJ, Shin JI, Shiri R, Shiue I, Shuval K, Siabani S, Siddiqi TJ, Silva DAS, Singh JA, Mtech AS, Skryabin VY, Skryabina AA, Soheili A, Spurlock EE, Stockfelt L, Stortecky S, Stranges S, Suliankatchi Abdulkader R, Tadbiri H, Tadesse EG, Tadesse DB, Tajdini M, Tariqujjaman M, Teklehaimanot BF, Temsah MH, Tesema AK, Thakur B, Thankappan KR, Thapar R, Thrift AG, Timalsina B, Tonelli M, Touvier M, TovaniPalone MR, Tripathi A, Tripathy JP, Truelsen TC, Tsegay GM, Tsegaye GW, Tsilimparis N, Tusa BS, Tyrovolas S, Umapathi KK, Unim B, Unnikrishnan B, Usman MS, Vaduganathan M, Valdez PR, Vasankari TJ, Velazquez DZ, Venketasubramanian N, Vu GT, Vujcic IS, Waheed Y, Wang Y, Wang F, Wei J, Weintraub RG, Weldemariam AH, Westerman R, Winkler AS, Wiysonge CS, Wolfe CDA, Wubishet BL, Xu G, Yadollahpour A, Yamagishi K, Yan LL, Yandrapalli S, Yano Y, Yatsuya H, Yeheyis TY, Yeshaw Y, Yilgwan CS, Yonemoto N, Yu C, Yusefzadeh H, Zachariah G, Zaman SB, Zaman MS, Zamanian M, Zand R, Zandifar A, Zarghi A, Zastrozhin MS, Zastrozhina A, Zhang ZJ, Zhang Y, Zhang W, Zhong C, Zou Z, Zuniga YMH, Murray CJL, Fuster V (2020) Global burden of cardiovascular diseases and risk factors, 1990-2019: update from the GBD 2019 study. J Am Coll Cardiol. 76(25): 2982-3021
Shao M, Yang W, Han G (2017) Protective effects on myocardial infarction model: delivery of schisandrin $\mathrm{B}$ using matrix metalloproteinase-sensitive peptide-modified, PEGylated lipid nanoparticles. Int J Nanomedicine. 12:7121-7130

Sharma G, She ZG, Valenta DT, Stallcup WB, Smith JW (2010) Targeting of macrophage foam cells in atherosclerotic plaque using oligonucleotide-functionalized nanoparticles. Nano Life. 1(3-4):207-214

Sharma AK, Kumar A, Taneja G, Nagaich U, Deep A, Datusalia AK, Rajput SK (2018) Combined and individual strategy of exercise generated preconditioning and low dose copper nanoparticles serve as superlative approach to ameliorate ISO-induced myocardial infarction in rats. Pharmacol Rep. 70(4):789-795

Sluimer JC, Daemen MJ (2009) Novel concepts in atherogenesis: angiogenesis and hypoxia in atherosclerosis. J Pathol. 218(1): 7-29

Somasuntharam I, Boopathy AV, Khan RS, Martinez MD, Brown ME, Murthy N, Davis ME (2013) Delivery of Nox2-NADPH oxidase siRNA with polyketal nanoparticles for improving cardiac function following myocardial infarction. Biomaterials. 34(31):7790-7798

Thirupathi G, Swetha E, Narendar D (2017) Role of isradipine loaded solid lipid nanoparticles on the pharmacodynamic effect in rats. Drug Res (Stuttg). 67(3):163-169

Tuerdi N, Xu L, Zhu B, Chen C, Cao Y, Wang Y, Zhang Q, Li Z, Qi R (2016) Preventive effects of simvastatin nanoliposome on isoproterenol-induced cardiac remodeling in mice. Nanomedicine. 12(7):1899-1907

Vicencio JM, Yellon DM, Sivaraman V, Das D, Boi-Doku C, Arjun S, Zheng Y, Riquelme JA, Kearney J, Sharma V, Multhoff G, Hall AR, Davidson SM (2015) Plasma exosomes protect the myocardium from ischemiareperfusion injury. J Am Coll Cardiol. 65(15):1525-1536

Xue HY, Liu S, Wong HL (2014) Nanotoxicity: a key obstacle to clinical translation of siRNA-based nanomedicine. Nanomedicine (Lond). 9(2):295-312

Zaragoza C, Gomez-Guerrero C, Martin-Ventura JL, BlancoColio L, Lavin B, Mallavia B, Tarin C, Mas S, Ortiz A, Egido J (2011) Animal models of cardiovascular diseases. J Biomed Biotechnol 2011:497841

Zhang JS (2005) F L, L H. Implications of pharmacokinetic behavior of lipoplex for its inflammatory toxicity. Adv Drug Deliv Rev. 57(5):689-698

Zhang XQ, Even-Or O, Xu X, van Rosmalen M, Lim L, Gadde S, Farokhzad OC, Fisher EA (2015) Nanoparticles containing a liver $\mathrm{X}$ receptor agonist inhibit inflammation and atherosclerosis. Adv Healthc Mater. 4(2):228-236

Zhang J, Xue Y, Ni Y, Ning F, Shang L, Ma A (2018) Size dependent effects of gold nanoparticles in ISO-induced hyperthyroid rats. Sci Rep. 8(1):10960

Publisher's note Springer Nature remains neutral with regard to jurisdictional claims in published maps and institutional affiliations. 